\title{
Romatoid Artrit Tedavisinde Akuaterapinin Etkinliği
}

\author{
The Effectiveness of Aquatic Exercises in the Treatment of Rheumatoid Arthritis
}

Tuncay Çakır, Fatma Deniz Evcik*, Volkan Subaşı**, ilknur Yiğit Gökçe***, Vural Kavuncu***

Antalya Eğitim ve Araştırma Hastanesi, Fizik Tedavi ve Rehabilitasyon Kliniği, Antalya, Türkiye

*Ankara Üniversitesi Haymana Meslek Yüksekokulu, Fizik Terapi ve Rehabilitasyon Anabilim Dalı, Ankara, Türkiye

**Özel Özgür Yaşam Fizik Tedavi ve Rehabilitasyon Merkezi, Mersin, Türkiye

${ }^{* * * A f y o n ~ K o c a t e p e ~ U ̈ n i v e r s i t e s i ~ T ı p ~ F a k u ̈ l t e s i, ~ F i z i k s e l ~ T ı p ~ v e ~ R e h a b i l i t a s y o n ~ A n a b i l i m ~ D a l ı, ~ A f y o n, ~ T u ̈ r k i y e ~}$

\section{Özet}

Amaç: Romatoid Artrit (RA) kronik destrüktif inflamatuvar bir hastalıktır. Bu çalışma RA tanısıyla takip ettiğimiz hastalarda akuaterapi ve balneoterapinin etkilerini araştırmak amacıyla planlanmıştır.

Gereç ve Yöntem: Çalışmaya Amerikan Romatizma Derneği (ACR) tanı kriterlerini dolduran ve RA tanısı konulan toplam 59 hasta dahil edildi. Hastalar randomize olarak üç gruba ayrıldılar. Grup $1(n=20)$ balneoterapi, grup $2(n=20)$ akuaterapi, grup $3(n=19)$ kontrol grubu olarak kabul edildi. Balneoterapi ve akuaterapi uygulamaları haftada beş gün, üç hafta süresince toplam 15 seans verildi. Hastalar klinik ve laboratuvar parametrelerce değerlendirildiler. Klinik değerlendirme; ağrı, sabah sertliği süresi, şiş ve hassas eklem sayısı, hastalık aktivite skorlaması (DAS28), Modifiye Sağlık Sorgulama Anketi (mHAQ), hastanın ve doktorun global değerlendirmesi ölçümünü içermektedir. Laboratuvar parametreler ise eritrosit sedimentasyon hızı (ESR), C-reaktif protein (CRP) olup tüm değerlendirme parametreleri tedavi öncesinde, tedavi sonrası (3. hafta) ve 3. ayda yapıldı.

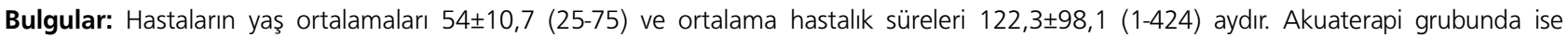
DAS 28 skorlarında ( $p<0,001)$, hassas nokta sayısında ( $p<0.005)$, GAS skorlarında $(p<0,005)$, mHAQ $(p<0,05)$, hastanın ve doktorun global değerlendirim sonuçlarında istatistiksel anlamlı düzelme olduğu gözlendi $(p<0,05)$. Sedimantasyon ve CRP değerleri istatistiksel anlamlı düşüktü $(p<0,05)$. Ancak gruplar arasında istatistiksel farklılık olmadığı gözlendi $(p>0,05)$.

Sonuç: Akuaterapi uygulamalarının RA tanılı hastalarda DAS28, ağı, yaşam kalitesi parametreleri üzerine olumlu etkileri olması nedeniyle tedavi protokolleri içerisinde göz önüne alınması gerektiğini düşünmekteyiz. (Türk Osteoporoz Dergisi 2014;20: 10-5)

Anahtar kelimeler: Romatoid, artrit, akuaterapi, egzersiz

\section{Summary}

Objective: Rheumatoid Arthritis (RA) is a chronic destructive inflammatory disorder. This study is aimed to investigate the effects of balneotherapy and aquatherapy in the treatment of RA patients.

Materials and Methods: A total of 59 patients who fulfilled the American College of Rheumatology diagnostic criteria for RA were included this study. Patients were randomly assigned into three groups. Group 1 ( $n=20)$ received balneotherapy, group 2 ( $n=20)$ received an aquatic exercise program and group $3(n=19)$ was accepted as control group. These programs were applied five times a week, over three weeks (15 sessions). Patients were evaluated for clinical and laboratory parameters. Clinical parameters included pain, duration of morning stiffness, number of swollen and tender joints, disease activity score (DAS28), Modified health assessment questionnaire (mHAQ), physician's and patient's global assessment and hand grip strength. Laboratory evaluation included erythrocyte sedimentation rate(ESR) and C-reactive protein (CRP). The assessment parameters were measured before, at the end of and after 3 months of the therapy.

Results: The mean age of the patients was $54 \pm 10.7$ (25-75) years and the mean disease duration was $122.3 \pm 98.1$ (1-424) months. In aquatic exercise group we observed an improvement in DAS28 scores $(p<0.001)$, in the number of tender joints $(p<0.005)$, in VAS scores ( $p<0.005)$, mHAQ $(p<0.05)$, physician's and patient's global assessments $(p<0.05)$. Also there was a statistically significant decrease in ESR results in aquatherapy group compared to other groups $(p<0.05)$. However no statistically significant difference was obtained between three groups ( $>>0.05)$.

Conclusion: This study shows that aquatic exercise program is beneficial in the management of DAS28, pain, HAQ parameters and should be taken in to consideration in planning exercise therapy for RA patients. (Turkish Journal of Osteoporosis 2014;20: 10-5)

Key words: Rheumatoid, arthritis, aquatic, exercises 


\section{Giriş}

Romatoid artrit (RA) etiyolojisi tam olarak bilinmeyen kronik inflamatuvar bir hastalık olup tedavisinde farmakolojik ajanların yanı sıra destek tedavileri de yer almaktadır $(1,2)$.

Ilık su içerisinde yapılan egzersizler akuaterapi olarak adlandırılmakta ve bir çok nörolojik ve kas iskelet sistemi hastalıklarının tedavisinde kullanılmaktadır. Akuaterapi; hidrostatik basıncın etkisiyle ödemin gerilemesi, kaslarda gevşeme, algojenik mediatörlerin dokudan uzaklaştırılması gibi faydalar sağlamaktadır. Ayrıca suyun kaldırma kuvveti sayesinde eklemlere binen yük azalmakta, su direncine karşı yapılan egzersizler ile kas güçlenmesi sağlanabilmektedir (3-6).

Balneoterapi ise belirli mineral yoğunluğuna ve sıcaklığa sahip sularda egzersiz yapmaksızın beklemek suretiyle uygulanan kür banyolarıdır. Termomineral su kaynaklarına sahip bölgelerde bir çok kas iskelet sistemi hastalığının rehabilitasyonunda balneoterapiden yararlanılmaktadır $(3,7,8)$.

Yapılan çalışmalarda romatoid artrit, ankliozan spondilit gibi inflamatuar kronik romatizmal hastalıklarda balneoterapi ve akuaterapinin; ağı ve hassas eklem sayısını azaltmanın yanında el kavrama gücünde artış, sabah tutukluğunda azalma gibi klinik paremetrelere olumlu etkilerinin olduğu gösterilmiştir (9-11). Bu nedenle literatür bilgisinden yola çıkılarak RA tanısıyla takip ettiğimiz hastalarda medikal tedavi dışında hastaların ağrı ve fonksiyonel kapasiteleri üzerine olumlu etki yapacağını düşündüğümüz akuaterapi ve balneoterapinin etkilerini araştırmak amacıyla çalışmamız planlanmıştır.

\section{Gereç ve Yöntem}

Çalışmaya Amerikan Romatizma Derneği (ACR) tanı kriterlerini dolduran ve RA tanısı konulan toplam 59 hasta dahil edildi. Hastalar randomize olarak üç gruba ayrıldılar. Grup 1 ( $n=20)$ balneoterapi, grup 2 ( $n=20)$ akuaterapi, grup $3(n=19)$ kontrol grubu olarak kabul edildi. Balneoterapi grubuna 20 dakika süreyle sadece termomineral banyo uygulaması yapıldı. Hastalardan sıcaklığı 36 derece, mineral yoğunluğu 1 gramın üzerindeki sodyum bikarbonatlı, termomineral su ile dolu küvette hareketsiz kalmaları istendi. Akuaterapi grubunda su içi egzersizler fizyoterapist eşliğinde gerçekleştirildi. Su içi egzersizler; üst ve alt ekstremite germe, eklem hareket açıklı̆ı̆, yürüme, postür ve propriosepsiyonu arttırmayı amaçlayan egzersizlerdi. Bu egzersizler sıcaklığı 28-30 derece olan tedavi havuzunda uygulandı. Egzersizler 10 kişilik gruplar halinde yaptırıldı. Yirmi gün sonunda su içi program sonlandırılarak RA hastalarına yönelik ev egzersiz programları tarif edildi ve günde 2 kez uygulamaları önerildi. Çalışmaya alınan hastalar da yan etki oluşmadı ve tüm hastalar tedavisini tamamladı.

Balneoterapi ve akuaterapi uygulamaları haftada beş gün, üç hafta süresince toplam 15 seans verildi. Hastalar klinik ve laboratuvar parametrelerce değerlendirildiler. Klinik değerlendirme; ağrı (Görsel Analog Skalası; GAS), sabah sertliği süresi, şiş ve hassas eklem sayısı, 28 eklemde hastalık aktivite skorlaması (DAS28), Modifiye Sağlık Sorgulama Anketi
(mHAQ), hastanın ve doktorun global değerlendirmesi (GAS) ölçümünü içermektedir. Laboratuvar parametreler ise eritrosit sedimentasyon hızı (ESR), C-reaktif protein (CRP) olup tüm değerlendirme parametreleri tedavi öncesinde, tedavi sonrası (3. hafta) ve 3. ayda yapıldılar.

Yüksek hastalık aktivitesi olanlar (DAS28>5,1), kaplıca tedavisine girmesine engel kontrolsüz hipertansiyon ve diabetes mellitus gibi sistemik bir hastalığı olanlar, iletişim sorunu ve kognitif bozukluğu olanlar ve aktif malignetisi olanlar çalışma dışı bırakıldı.

Hastalardan bilgilendirilmiş gönüllü olur formunu doldurmaları istendi. Ayrıca çalışma için Kocatepe Üniversitesi Etik Kurulu'ndan onay alındı.

\section{İstatistiksel Analiz}

Verilerin dağılımı Tek Örneklem Kolmogorov - Simirnov testi ile incelendi. Gruplar arası karşılaştırmalar One-Way ANOVA testi ile yapıldı. Grup içi tedavi öncesi ve tedavi sonrası karşılaştırmalar Wilcoxon t testi ile incelendi. $p<0,05$ anlamlılık sınırı olarak kabul edildi. İstatiksel değerlendirmeler SPSS 10 paket program ile yapıldı.

\section{Bulgular}

Hastaların yaş ortalamaları 54 $\pm 10,7$ (25-75) ve ortalama hastalık süreleri 122,3ะ98,1 (1-424) aydı. Hastaların demografik verileri Tablo 1'de sunulmuştur.

Tedavi sonrası 3. haftada gerçekleştirilen ilk kontrolde; balneoterapi grubunda DAS28 skorlarında azalma tespit edildi ancak bu azalma istatistiksel anlamlı değildi $(p=0,22)$. Hassas nokta sayısında, GAS skorlarında, mHAQ skorlarında, hastanın ve doktorun global değerlendirim sonuçlarında, sedimantasyon ve CRP değerlerinde ise istatistiksel anlamlı fark saptanmadı $(p>0,05)$.

Akuaterapi grubunda ise DAS28 skorlarında $(p<0,001)$, hassas nokta sayısında $(p<0,005)$, GAS skorlarında $(p<0,005)$, mHAQ $(p<0,05)$, hastanın ve doktorun global değerlendirim sonuçlarında istatistiksel anlamlı düzelme olduğu gözlendi $(p<0,05)$. Sedimantasyon ve CRP değerleri istatistiksel anlamlı düşüktü $(p<0,05)$. Ancak gruplar arasında istatistiksel farklılık olmadığı gözlendi ( $p>0,05)$.

Kontrol grubunda ise klinik ve laboratuvar parametreleri arasında istatistiksel anlamlı farklılık yoktu $(p>0,05)$.

Üçüncü ay kontrolde ise; balneoterapi grubunda, DAS28 skorlarında, hassas nokta sayısında, GAS skorlarında, mHAQ skorlarında, hastanın ve doktorun global değerlendirim sonuçlarında, ESR ve CRP değerlerinde istatistiksel anlamlı farklılık yoktu $(p>0,05)$.

Akuaterapi grubunda ise, DAS28 $(p=0,003)$, hassas nokta sayısı $(p=0,027)$, GAS skorlarında $(p=0,012), m H A Q$ skorlarında $(p=0,029)$, hastanın global değerlendirim $(p=0,027)$, doktorun global değerlendirim sonuçlarında $(p=0,024)$ istatistiksel anlamlı düzelme bulundu. Benzer şekilde ESR ve CRP değerlerinde de istatistiksel anlamlı düşme saptandı (sırasıyla $p=0,004$, $p=0,0012)$. Ancak gruplar arasında istatistiksel fark olmadığı gözlendi $(p>0,05)$. 
Tablo 1. Hastaların demografik verileri

\begin{tabular}{|l|l|l|c|l|}
\hline & Balneoterapi & Akuaterapi & Kontrol & p \\
\hline Yaş (yıl) & $53,10 \pm 12,38$ & $55,00 \pm 8,97$ & $47,15 \pm 9,56$ & 0,056 \\
\hline Hastalık süresi (ay) & $111,75 \pm 94,28$ & $133,53 \pm 103,54$ & $58,35 \pm 50,07$ & 0,023 \\
\hline Cinsiyet (kadın/erkek) & $12 / 8$ & $13 / 7$ & $12 / 7$ & 0,949 \\
\hline Veriler ortalama \pm standart sapma olarak ifade edildi
\end{tabular}

Tablo 2. Hastaların başlangıç, tedavi sonrası 1. ay ve 3. ay kontrolündeki hastalık aktivite düzeyleri-1

\begin{tabular}{|c|c|c|c|c|}
\hline & Balneoterapi & Akuaterapi & Kontrol & $p$ \\
\hline DAS28 0 & $3,08 \pm 0,94$ & $3,83 \pm 0,80$ & $2,95 \pm 0,94$ & 0,07 \\
\hline DAS28 1 & $2,64 \pm 0,81$ & $3,26 \pm 0,71$ & $2,96 \pm 0,63$ & 0,034 \\
\hline$p(0-1)$ & 0,22 & 0,000 & 0,940 & \\
\hline DAS28 3 & $3,06 \pm 0,92$ & $3,23 \pm 0,73$ & $3,05 \pm 0,69$ & 0,706 \\
\hline$p(0-3)$ & 0,913 & 0,003 & 0,663 & \\
\hline Hassas Eklem Sayısı 0 & $2,05 \pm 3,58$ & $2,80 \pm 2,02$ & $1,84 \pm 3,20$ & 0,577 \\
\hline Hassas Eklem Sayısı 1 & $0,95 \pm 1,31$ & $1,90 \pm 1,74$ & $1,59 \pm 3,79$ & 0,474 \\
\hline$p(0-1)$ & 0,206 & 0,014 & 0,470 & \\
\hline Hassas Eklem Sayısı 3 & $2,11 \pm 2,72$ & $2,00 \pm 2,34$ & $2,05 \pm 3,25$ & 0,993 \\
\hline$p(0-3)$ & 0,430 & 0,027 & 0,734 & \\
\hline GAS $(\mathrm{cm}) 0$ & $2,95 \pm 3,32$ & $4,22 \pm 2,12$ & $1,71 \pm 2,59$ & 0,021 \\
\hline GAS $(\mathrm{cm}) 1$ & $2,42 \pm 2,91$ & $3,50 \pm 2,28$ & $1,82 \pm 3,04$ & 0,177 \\
\hline$p(0-1)$ & 0,558 & 0,031 & 0,557 & \\
\hline GAS $(\mathrm{cm}) 3$ & $2,11 \pm 2,28$ & $3,60 \pm 2,28$ & $2,11 \pm 2,82$ & 0,101 \\
\hline$p(0-3)$ & 0,333 & 0,012 & 0,363 & \\
\hline mHAQ 0 & $0,68 \pm 0,82$ & $0,40 \pm 0,46$ & $0,59 \pm 0,55$ & 0,367 \\
\hline mHAQ 1 & $0,62 \pm 0,76$ & $0,34 \pm 0,42$ & $0,57 \pm 0,61$ & 0,311 \\
\hline$p(0-1)$ & 0,138 & 0,019 & 0,945 & \\
\hline mHAQ 2 & $0,411 \pm 0,51$ & $0,33 \pm 0,42$ & $0,57 \pm 0,59$ & 0,336 \\
\hline$p(0-3)$ & 0,139 & 0,029 & 0,837 & \\
\hline \multicolumn{5}{|c|}{$\begin{array}{l}\text { DAS28: Hastalık Aktivite Skorlaması, GAS: Görsel Analog Skalası } \\
\text { mHAQ: Modifiye Sağlik Sorgulama Anketi } \\
\text { Veriler ortalama } \pm \text { standart sapma olarak ifade edildi }\end{array}$} \\
\hline
\end{tabular}

Kontrol grubunda ise klinik ve laboratuvar parametreleri arasında istastistiksel anlamlı farklılık yoktu $(p>0,05)$. Tedavi öncesi, tedavi sonrası 1. ay ve 3. ay kontroldeki hastalık aktivitesi ile ilgili veriler Tablo 2 ve Tablo 3'de sunulmuştur.

\section{Tartışma}

Romatoid artrit tedavisinde özürlülük gelişimine engel olabilmek için farmakolojik tedavinin yanında nonfarmakolojik tedavi yaklaşımlarının gerekliliği son yıllarda gittikçe önem kazanmaktadır. Balneoterapi bu tedavi yaklaşımlarından bir tanesidir ve osteoartrit başta olmak üzere birçok romatizmal hastalığın tedavisinde kullanılmıştır. Sadece osteoartrit değil psöriatik artrit gibi inflamatuvar hastalıklarda etkin olduğunu gösteren çalışmalar vardır $(12,13)$.

Romatoid artritte radonlu ve karbondioksitli banyoların etkinliğinin kıyaslandığı bir çalısmada her iki banyo türünde de ağrı düzeylerinde ve fonksiyonel durumda iyileşme olduğu belirtilmiştir (14). Mustur ve arkadaşlarının romatoid artritte balneoterapinin etkinliğini araştırdıkları çalışmada $\mathrm{mHAQ}$ ve SF-36 skorlarında düzelme olduğu belirtilmiştir (15). Stojanovic ve arkadaşlarının romatoid artritte de fizik tedavi yöntemleri ile kombine olarak balneoterapi kullanılmasının DAS28 skorlarında ve yaşam kalitesi parametrelerinde düzelme sağladığı belirtilmiştir (16). Bizim çalışmamızda da balneoterapi grubunda ilk kontrolde, DAS28 skorlarında düzelme kaydedilmiştir. Balneoterapinin etki mekanizmaları kesinlik kazanmamakla birlikte olası etki mekanizmaları arasında mekanik, kimyasal ve termal etkiler söz konusu olmaktadır (17). Romatoid artritli hastalarda anksiyete ve depresyon sıklığının arttığı balneoterapinin serotonin sistemi aktivasyonu ile kendini daha iyi hissetme ve duygu durum 
üzerine olumlu etkileri olduğu da çalışmalarla gösterilmiştir $(18,19)$. Hastanın duygu durumunun düzelmesinin ve ağrılarının azalmasının hastalık aktivite skorlarına olumlu yansıdığını düşünmekteyiz.

Romatoid artrit tedavisinde rehabilitasyon programının önemi göz ardı edilmemekte ve son yıllarda bu konudaki çalışmalar gittikçe artmaktadır. Özellikle kas gücü ve eklem hareket açıklığını korumaya yönelik egzersizler önemli yer tutmaktadır (20-22). Hsieh ve arkadaşları romatoid artritli hastalarda evde ve gözetim altında yapılan aerobik egzersizlerin etkinliğini karşılaştırdıkları çalışmada, aerobik kapasitenin gözetim altında olan hastalarda istatistiksel anlamlı olarak yüksek bulmuşlardır (23).

Romatizmal hastalıkların tedavisinde karasal egzersizler kadar su içi akuatik egzersizler de önerilmektedir. Suomi ve arkadaşlarının dejeneratif ve inflamatuvar artriti olan 30 hastada yaptığı çalışmada; su içi egzersiz ve kara egzersiz gruplarında kontrol grubuna göre fonksiyonel kapasitede ve günlük yaşam aktivite testlerinde düzelme sağlanmıştır (24).

Takken ve ark.'nın juvenil idiopatik artritte akuaterapinin etkinliğini araştırdıkları çalışmalarında, kontrol grubuna göre

\section{Tablo 3. Hastaların başlangıç, tedavi sonrası 1. ay ve 3. ay kontrolündeki hastalık aktivite düzeyleri-2}

\begin{tabular}{|c|c|c|c|c|}
\hline & Balneoterapi & Akuaterapi & Kontrol & $p$ \\
\hline $\begin{array}{l}\text { Hastanın değerlendirimi } \\
(\mathrm{GAS}, \mathrm{cm}) 0\end{array}$ & $4,40 \pm 2,94$ & $4,05 \pm 1,84$ & $4,05 \pm 2,83$ & 0,887 \\
\hline $\begin{array}{l}\text { Hastanın değerlendirimi } \\
(\mathrm{GAS}, \mathrm{cm}) 1\end{array}$ & $3,31 \pm 2,33$ & $3,05 \pm 1,93$ & $4,11 \pm 2,66$ & 0,360 \\
\hline$p(0-1)$ & 0,092 & 0,007 & 0,878 & \\
\hline $\begin{array}{l}\text { Hastanın değerlendirimi } \\
(\mathrm{GAS}, \mathrm{cm}) 3\end{array}$ & $3,84 \pm 2,63$ & $3,05 \pm 1,99$ & $3,47 \pm 2,43$ & 0,580 \\
\hline$p(0-3)$ & 0,503 & 0,0027 & 0,186 & \\
\hline $\begin{array}{l}\text { Doktorun değerlendirimi } \\
(\mathrm{GAS}, \mathrm{cm}) 0\end{array}$ & $3,30 \pm 2,49$ & $3,40 \pm 1,60$ & $2,57 \pm 1,60$ & 0,368 \\
\hline $\begin{array}{l}\text { Doktorun değerlendirimi } \\
(\mathrm{GAS}, \mathrm{cm}) 1\end{array}$ & $2,36 \pm 1,83$ & $2,45 \pm 1,63$ & $2,70 \pm 1,75$ & 0,835 \\
\hline$p(0-1)$ & 0,05 & 0,001 & 0,854 & \\
\hline $\begin{array}{l}\text { Doktorun değerlendirimi } \\
(\mathrm{GAS}, \mathrm{cm}) 3\end{array}$ & $2,89 \pm 2,10$ & $2,55 \pm 1,82$ & $2,74 \pm 1,79$ & 0,853 \\
\hline$p(0-3)$ & 0,428 & 0,024 & 0,420 & \\
\hline Sedimantasyon Hızı 0 & $20,45 \pm 11,21$ & $30,0 \pm 16,76$ & $24,0 \pm 16,34$ & 0,134 \\
\hline Sedimantasyon Hızı 1 & $19,8 \pm 10,99$ & $22,8 \pm 7,85$ & $25,3 \pm 14,80$ & 0,354 \\
\hline$p(0-1)$ & 0,571 & 0,015 & 0,875 & \\
\hline Sedimantasyon Hızı 3 & $21,78 \pm 10,94$ & $21,65 \pm 9,08$ & $25,36 \pm 18,06$ & 0,616 \\
\hline$p(0-3)$ & 0,936 & 0,004 & 0,727 & \\
\hline CRP 0 & $7,48 \pm 6,80$ & $15,0 \pm 16,32$ & $7,43 \pm 6,62$ & 0,051 \\
\hline CRP 1 & $7,20 \pm 8,20$ & $9,76 \pm 7,26$ & $8,30 \pm 10,54$ & 0,656 \\
\hline$p(0-1)$ & 0,281 & 0,042 & 0,826 & \\
\hline CRP 3 & $9,46 \pm 9,07$ & $10,44 \pm 9,24$ & $14,69 \pm 22,11$ & 0,511 \\
\hline$p(0-3)$ & 0,307 & 0,0012 & 0,554 & \\
\hline \multicolumn{5}{|c|}{$\begin{array}{l}\text { GAS: Görsel Analog Skalası, CRP: C-reaktif protein } \\
\text { Veriler ortalama } \pm \text { standart sapma olarak ifade edildi }\end{array}$} \\
\hline
\end{tabular}


fonksiyonel kapasitede artış ve hastalık aktivite skorlarında düzelme olduğunu ancak bu düzelmenin istatistiksel olarak anlamlı olmadığını belirtilmişlerdir (25). Tomas-carrus ve ark.'nın çalışmasında akuaterapi programlarının fiziksel kondüsyonun, genel sağlığın ve emosyonel durumun iyileştirilmesinde olumlu etkileri olduğunu belirtmişlerdir (26). Bizim çalışmamızda da akuaterapi grubunda hastalık aktivite skorlarında istatistiksel anlamlı düzelme kaydedilmiştir. Su içinin egzersiz için ideal bir ortam oluşturmasının, egzersizlerin daha ağrısız yapılabilmesi, tedavinin başlangıç aşamasında hastaların motivasyonunu arttırarak egzersizlerini daha düzenli yapmalarını sağlayarak, iyileşmeyi ve ağrıda daha fazla azalmayı sağlayarak etkili olabileceğini düşünmekteyiz.

Literatürde inflamatuvar artritlerde egzersizlerin fonksiyonel durum ve laboratuvar parametrelerine etkisi araştırıldığında bir çok çalışmaya rastlanmıştır. Buljina ve arkadaşlarının çalışmasında romatoid artritte 3 hafta boyunca uygulanan egzersiz ve fizik tedavi grubunda kontrol grubuna göre ESR'deki azalmanın daha fazla olduğunu, ancak istatistiksel olarak anlamlı olmadığını belirtmişler ancak bu etkinin nasıl meydana geldiğini açıklamanın ise zor olduğunu söylemişlerdir (27). Romatoid artritte egzersizler immün sistem hücreleri üzerinde etkili olarak hastalık aktivitesi üzerinde olumlu etkiler sağlayabilmektedir. Navarro ve ark.'nın çalışmasında tip 2 kollojen ile indüklenen artriti olan ratlara 6 hafta boyunca yüzme egzersizleri verilmiş, immun sistem hücrelerinin inaktive olduğunu, plazma kortizol ve interlökin-2 düzeylerinin ise yükseldiğini belirtmişlerdir (28). Bizim çalışmamızda da akuaterapi grubunda ESR de düşüş daha fazla olmuştur. Mekanizması net olmasa da plazma kortizol düzeylerindeki yükselmenin ESR düşüşünde etkili olabileceğini düşünmekteyiz.

Akuaterapi programlarının optimum süresi konusunda kesin bir fikir birliği bulunmamaktadır. Çalışmalarda ortalama 12 haftalık egzersiz programlarına yer verilmiştir $(7,29)$. Bizim çalışmamızda 3 haftalık bir program haftada 5 gün uygulanmıştır. Daha uzun süreli egzersiz programı ile daha iyi sonuçlar alınabileceği göz önüne alınmalıdır. Herhangi bir kontrendikasyonu olmayan her hastada su içi egzersizler sağladıkları bir çok avantajları nedeniyle güvenle önerilebilir. Egzersiz ortamı olarak su içinin kullanılmasının getirdiği bir çok olumlu faktörün yanında, bu konuda deneyimli personel azlığı, egzersiz yapmaya uygun havuz ortamlarının bulunmasında güçlükler, tedavi için harcanan zamanın daha fazla olması, kara egzersizlerine göre biraz daha fazla ek maliyet gerektirmesi akuaterapi programlarını sınılayan en önemli etkenler olarak görünmektedir. Biz çalışmamı sonucunda, romatoid artritte akuaterapi programlarının, hem laboratuvar hem de klinik parametreler üzerine etkili bir yöntem olduğu, ancak bu sonucun yapılacak yeni çalışmalarla desteklenmesi gerektiği kanısına vardık. Hasta sayımızın az olması, hastaların tedavi sürelerinin kısalığı ve takip süremizin kısa olması çalışmamızın eksik yönleridir.

\section{Sonuç}

Akuaterapi uygulamalarının RA tanılı hastalarda DAS28, ağrı, yaşam kalitesi parametreleri üzerine olumlu etkileri olması nedeniyle tedavi protokolleri içerisinde göz önüne alınması gerektiğini düşünmekteyiz.

\section{Kaynaklar}

1. Christie A, Jamtvedt G, Dahm KT, Moe RH, Haavardsholm EA, Hagen KB. Effectiveness of nonpharmacological and nonsurgical interventions for patients with rheumatoid arthritis: An overview of systematic reviews. Phys Ther 2007:87:1697-715.

2. Anain JM Jr, Bojrab AR, Rhinehart FC. Conservative treatments for rheumatoid arthritis in the foot and ankle. Clin Podiatr Med Surg 2010;27:193-207

3. Kamioka $H$, Tsutani $K$, Okuizumi $H$, Mutoh $Y$, Ohta M, Handa $S$, at al. Effectiveness of aquatic exercise and balneotherapy: A summary of systematic reviews based on randomized controlled trials of water immersion therapies. J Epidemiol 2010;20:2-12.

4. Salem $Y$, Scott AH, Karpatkin H, Concert G, Haller L, Kaminsky E, at al. Community-based group aquatic programme for individuals with multiple sclerosis: a pilot study. Disabil Rehabil 2011;33:720-8.

5. Valtonen A,Pöyhönen T, Sipilä S, Heinonen A. Effects of aquatic resistance training on mobility limitation and lower-limb impairments after knee replacement. Arch Phys Med Rehabil 2010;9:833-9.

6. Kulisch A, Bender T, Németh A, Szekeres L. Effect of thermal water and adjunctive electrotherapy on chronic low back pain: a double-blind, randomized, follow-up study. J Rehabil Med 2009;41:73-9.

7. Gaál J, Varga J, Szekanecz Z, Kurkó J, Ficzere A, Bodolay E, at al. Balneotherapy in elderly patients: effect on pain from degenerative knee and spine conditions and on quality of life. Isr Med Assoc J 2008; 10:365-9.

8. Nocco PB. Mineral water as a cure. Veroff Schweiz Ges Gesch Pharm 2008;29:13-402.

9. Nasermoaddeli A, Kagamimori S. Balneotherapy in medicine: A review. Environ Health Prev Med 2005;10:171-9.

10. Van Tubergen A, Boonen A, Landewé R, Rutten-Van Mölken M, Van Der Heijde D, Hidding A, et al. Cost effectiveness of combined spa-exercise therapy in ankylosing spondylitis: a randomized controlled trial. Arthritis Rheum 2002;47:459-67.

11. Al-Qubaeissy KY, Fatoye FA, Goodwin PC, Yohannes AM. The effectiveness of hydrotherapy in the management of rheumatoid arthritis: a systematic review. Musculoskeletal Care 2013;11:3-18.

12. Sukenik S, Baradin R, Codish S, Neumann L, Flusser D, Abu-Shakra M, Buskila D. Balneotherapy at the Dead Sea area for patients with psoriatic arthritis and concomitant fibromyalgia. Isr Med Assoc J 2001;3:147-50.

13. Elkayam O, Ophir J, Brener S, Paran D, Wigler I, Efron D, et al. Immediate and delayed effects of treatment at the Dead Sea in patients with psoriatic arthritis. Rheumatol Int 2000;19:77-82.

14. Franke A, Reiner L, Pratzel HG, Franke T, Resch KL. Longterm efficacy of radon spa therapy in rheumatoid arthritis-a randomized, sham-controlled study and follow-up. Rheumatology (Oxford) 2000;39:894-902.

15. Mustur D, Vesovic-Potic V, Vujasinovic-Stupar N, Ille T. Beneficial effects of spa treatment on functional status and quality of life of patients with rheumatoid arthritis. Srp Arh Celok Lek 2008;136:391-6.

16. Stojanovic S, Dimic A, Stamenkovic B, Stankovic A, Nedovic J. Influence of balneophysical therapy on activity, functional capacity, and quality of life in patients with rheumatoid arthritis. Srp Arh Celok Lek 2009;137:171-4.

17. Kamioka H, Nakamura $Y$, Okada S, Kitayuguchi J, Kamada M, Honda T, Matsui Y, Mutoh Y. Effectiveness of comprehensive health education combining lifestyle education and hot spa bathing for male white-collar employees: a randomized controlled trial with 1-year follow-up. J Epidemiol 2009;19:219-30.

18. Marazziti D, Baroni S, Giannaccini G, Catena Dell'Osso M, Consoli G, Picchetti M, Carlini M, Massimetti G, Provenzano S, Galassi A. Thermal balneotherapy induces changes of the platelet serotonin transporter in healthy subjects. Prog Neuropsychopharmacol Biol Psychiatry 2007;31:1436-9.

19. Altan L, Bingöl Ü, Sağırkaya Z, Sarandöl A, Yurtkuran M. Romatoid artritli hastalarda anksiyete ve depresyon. Romatizma 2004;19:7-13. 
20. Balaban B, Tan A. K, Alaca R. Romatoid artrit tedavisinde nonfarmakolojik yaklaşımlar. Romatizma 2002;17:48-55.

21. Law RJ, Breslin A, Oliver EJ. Perceptions of the effects of exercise on joint health in rheumatoid arthritis patients. Rheumatology (Oxford) 2010;49: 2444-51.

22. Hurkmans EJ, Maes S, de Gucht V, Knittle K, Peeters AJ, Ronday $\mathrm{HK}$, at al. Motivation as a determinant of physical activity in patients with rheumatoid arthritis. Arthritis Care Res (Hoboken) 2010;62:371-7.

23. Hsieh LF, Chen SC, Chuang CC, Chai HM, Chen WS, He YC. Supervised aerobic exercise is more effective than home aerobic exercise in female chinese patients with rheumatoid arthritis. J Rehabil Med 2009;41:332-7.

24. Suomi R, Collier D. Effects of arthritis exercise programs on functional fitness and perceived activities of daily living measures in older adults with arthritis. Arch Phys Med Rehabil 2003;84:158994
25. Takken T, Van Der Net J, Kuis W, Helders PJ. Aquatic fitness training for children with juvenile idiopathic arthritis. Rheumatology (Oxford) 2003;42:1408-14

26. Tomas-Carus $P$, Häkkinen A, Gusi N, Leal A, Häkkinen K, OrtegaAlonso A. Aquatic training and detraining on fitness and quality of life in fibromyalgia. Med Sci Sports Exerc 2007;39:1044-50

27. Buljina Al, Taljanovic MS, Avdic DM, Hunter TB. Physical and exercise therapy for treatment of the rheumatoid hand. Arthritis Rheum 2001;45:392-7

28. Navarro F, Bacurau AV, Almeida SS, Barros CC, Moraes MR, Pesquero JL, at al. Exercise prevents the effects of experimental arthritis on the metabolism and function of immune cells. Cell Biochem Funct. 2010;28:266-73.

29. Gusi N, Tomas-Carus $P$, Häkkinen A, Häkkinen K, Ortega-Alonso A. Exercise in waist-high warm water decreases pain and improves health-related quality of life and strength in the lower extremities in women with fibromyalgia. Arthritis Rheum 2006;55:66-73. 